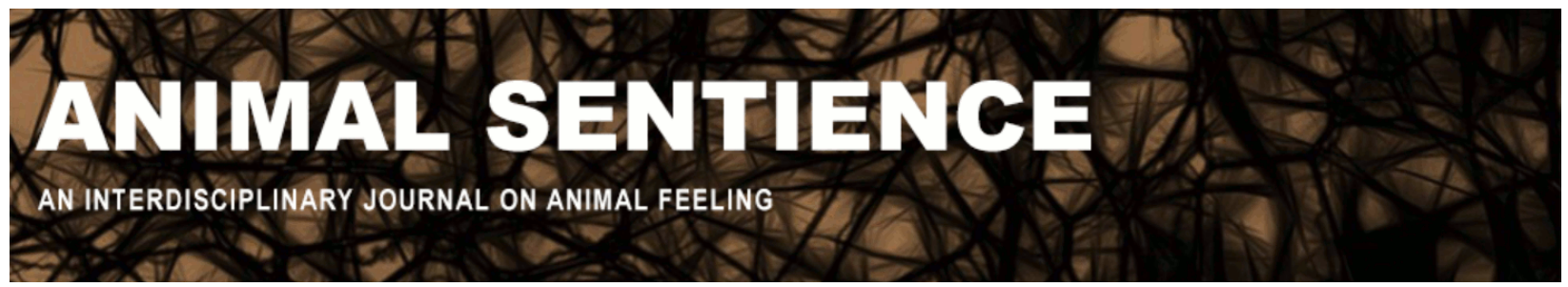

Marzluff, John M. (2020) Bridging the empathy gap for invertebrates. Animal Sentience 29(22)

DOI: 10.51291/2377-7478.1614

Date of submission: 2020-07-04

Date of acceptance: 2020-07-07

(c)

This article has appeared in the journal Animal

Sentience, a peer-reviewed journal on animal

cognition and feeling. It has been made open access,

free for all, by WellBeing International and deposited

in the WBI Studies Repository. For more information,

please contact

wbisr-info@wellbeingintl.org.

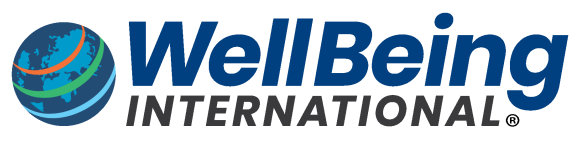

SOLUTIONS FOR PEOPLE, ANIMALS AND ENVIRONMENT 


\title{
Bridging the empathy gap for invertebrates
}

Commentary on Mikhalevich \& Powell on Invertebrate Minds

\author{
John M. Marzluff \\ School of Environmental and Forest Sciences, University of Washington
}

\begin{abstract}
The actions of sentient vertebrates command our attention and inform our morality. Mikhalevich \& Powell (2020) (M\&P) argue that similar activities in a wide range of invertebrates with central nervous systems should do likewise. However, humans most readily empathize with creatures we recognize as similar in behavior, physiology, or appearance to ourselves. Helping humanity overcome this bias is a significant challenge for those who study invertebrates. Until this empathy gap is bridged, I believe few people and the policies they craft will afford invertebrates the moral standing that M\&P argue they deserve. Therefore, I suggest those interested in raising appreciation for invertebrate minds should broaden the impact of their research findings. They should consider informing the lay public, especially children, through writing, speaking, and seeking non-traditional collaborations with artists, filmmakers, musicians, game developers, and others that affect popular culture.
\end{abstract}

John Marzluff is the James W. Ridgeway Professor of Forest Resources. He is a wildlife scientist who studies the impacts of human actions on birds in urban, agricultural, and wildland areas. His research on crows, ravens, and other birds also asks how these creatures affect human culture. Website

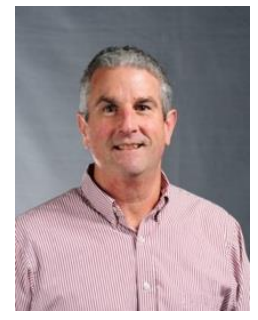

1. A Real Difference. Last week, stopped in a traffic jam of nearly 50 vehicles, my wife, two students, and I watched hundreds of American bison gather in the Lamar Valley of Yellowstone National Park. The bison, mostly females in the company of their calves and yearlings, were running toward a dark lump on the green valley floor. Dozens of the large mammals circled the heap, clockwise, forming a tornado of dust, fur, and horns. As they passed the object, which we quickly ascertained was a dead cow, they paused to look, sniff, and lick the corpse. A wolf, intent on scavenging a meal, was immediately escorted away from the dead by two aggressive cows, whose raised tails and direct approach made their intentions clear. The amassed bison also kept ravens from scavenging. The wolf retreated, tail between its legs. It and the gathering ravens would wait for the procession to end. So too would the many humans who watched the funeral in awe. As the day wore on, the bison drifted away. That is, all but one yearling. This female, almost certainly the daughter of the bison that lay dead beside Rose Creek, stood alongside the corpse, nodding, and bellowing. Perhaps she was trying to wake her mother. Or, she was merely confused. Or, and I doubt anyone who observed her would think otherwise, she was mourning the loss of a loved one.

I was prepared for this encounter, as I'd seen a bison funeral before, but I suspect few in the crowd had been so lucky. My wife and students were deeply moved by the experience, a 
highlight of a trip full of great encounters. I do not doubt that their empathy for bison, and perhaps other mammals, was raised by their experience. Surely, the compassion of the general public that witnessed the funeral was also enhanced. Animals that behave in ways we can relate to have such power. Those that are more alien do not yet possess such influence. I've watched army ants form living bridges, and tropical spiders wait with nets to ambush prey, but these extraordinary times, while inspiring awe, failed to inspire empathy. Mikhalevich \& Powell (2020) (M\&P) aptly discuss this point and possible explanations for such bias. Others reiterated it in commentaries (e.g., Monsó \& Osuna-Mascaró 2020, Woodruff 2020). Bridging this empathy gap is to me the central challenge that M\&P face in convincing our species to confer moral standing on many invertebrates.

The literature documents a preference for animals that humans perceive as cognitively similar to themselves (Serpell 2004, Marzluff \& Swift 2017). M\&P provide a convincing list of invertebrate behaviors that would cause some of us to carefully plan humane experiments and conceive of non-lethal pest control, just as we do for vertebrates. But they do not consider practical ways to increase awareness of these attributes so they might raise empathy for smallbrained, unfamiliar, and disgust-provoking species. In their words, how to debunk the "invertebrate dogma."

2. Spreading the Word. My experiences with crows and ravens, birds reviled by many people because of their traditional association with ominous events, such as death (Marzluff \& Angell 2005), suggest to me that scientists wishing to enlighten people about the sentience of invertebrate life will need to broaden their outreach vastly. Publishing our findings of crow neural networks underlying fear and learning set the basis for greater societal acceptance of these birds. But demonstrations that crows recognize people and spread information about them through social learning appeared to be more engaging to the average person than were brain images. People saw themselves from the crow's perspective. And, engagement rarely came from a direct reading of our articles in scientific journals. Instead, it came through reading our popular books and social media posts, interacting with us at public talks, and primarily through widespread dissemination of documentaries about our work. How might this approach be used to raise awareness of invertebrate sentience and build empathy for these underappreciated animals?

Enhancing the natural proclivity of children to wonder about the natural world is an essential first step. Children who experience nature develop environment-friendly behaviors (Collado et al. 2013), so childhood exposure to flexible invertebrate behaviors may build empathy as they see more of themselves in the butterflies they pursue or the ants they harass. Once interested, a child's knowledge can be expanded to considerations of sentience during interactions with invertebrate experts at summer camps, museums, and schools.

Popular books with intriguing titles, such as Bumblebee Economics (Heinrich 1979) or Honeybee Democracy (Seeley 2010), can inform the general public about the flexible behaviors of invertebrates. Drawing parallels between farming and ranching in insect and human societies might further pique and inform readers' curiosity (Marzluff 2020). Increasing knowledge about unusual invertebrate behavior may increase people's empathy, as it does for biodiversity in general (Martín-López et al. 2007). Future works such as these could also introduce the reader to the debate about sentience. 
To broaden their audience more effectively, invertebrate biologists should seek nontraditional collaborations, beyond those with journalists, curators, and filmmakers. Working with poets, artists, musicians, architects, and game developers may help put invertebrate sentience more squarely in the public consciousness.

When scientific understanding of the sentient world of invertebrates begins to permeate popular culture, I believe people will become more compassionate about the treatment of invertebrate pests and the conservation of rare species (Marzluff and Swift 2017). In so doing, we may begin to afford these vital species moral standing.

\section{References}

Collaldo, S., Staats, H. \& Corraliza, J. (2013) Experiencing nature in children's summer camps: affective, cognitive and behavioural consequences. Journal of Environmental Psychology 33:37-44.

Heinrich, B. (1979) Bumblebee Economics. Harvard University Press, Cambridge, MA.

Martín-López, B., Montes, V. \& Benayas, J. (2007) The non-economic motives behind willingness to pay for biodiversity conservation. Biological Conservation 139:67-82.

Marzluff, J. M. (2020) In Search of Meadowlarks. Yale University Press, New Haven, CT.

Marzluff, J. M. \& Angell, T. (2005) In the Company of Crows and Ravens. Yale University Press, New Haven, CT.

Marzluff, J. M. \& Swift, K. N. (2017) Connecting animal and human cognition to conservation. Current Opinion in Behavioral Sciences 16:87-92.

Mikhalevich, I. \& Powell, R. (2020) Minds without spines: Evolutionarily inclusive animal ethics. Animal Sentience 29(1).

Monsó, S. \& Osuna-Mascaró, A. J. (2020) Problems with basing insect ethics on individuals' welfare. Animal Sentience 29(8).

Seeley, T. D. (2010) Honeybee Democracy. Princeton University Press, Princeton, NJ.

Serpell, J. A. (2004) Factors influencing human attitudes to animals and their welfare. Animal Welfare 13:S145-S151.

Woodruff, M. L. (2020) Whether invertebrates are sentient matters to bioethics and science policy. Animal Sentience 29(16). 